\title{
Feel4Diabetes healthy diet score: development and evaluation of clinical validity
}

Eeva Virtanen ${ }^{1 *}$ (D), Jemina Kivelä ${ }^{1,2}$, Katja Wikström ${ }^{1,3}$, Christina-Paulina Lambrinou ${ }^{4}$, Pilar De Miguel-Etayo, Nele Huys ${ }^{6}$, Katalin Vraukó-Tóth7, Luis A. Moreno ${ }^{5}$, Natalya Usheva ${ }^{8}$, Nevena Chakarova ${ }^{9}$, Sándorné A. Rado ${ }^{7}$, Violeta lotova ${ }^{10}$, Konstantinos Makrilakis ${ }^{11}$, Greet Cardon ${ }^{6}$, Stavros Liatis ${ }^{11}$, Yannis Manios ${ }^{4}$, Jaana Lindström ${ }^{1}$ and on behalf of the Feel4Diabetes research group

\begin{abstract}
Background: The aim of this paper is to present the development of the Feel4Diabetes Healthy Diet Score and to evaluate its clinical validity.

Methods: Study population consisted of 3268 adults (63\% women) from high diabetes risk families living in 6 European countries. Participants filled in questionnaires at baseline and after 1 year, reflecting the dietary goals of the Feel4Diabetes intervention. Based on these questions the Healthy Diet Score was constructed, consisting of the following components: breakfast, vegetables, fruit and berries, sugary drinks, whole-grain cereals, nuts and seeds, low-fat dairy products, oils and fats, red meat, sweet snacks, salty snacks, and family meals. Maximum score for each component was set based on its estimated relative importance regarding T2DM risk, higher score indicating better quality of diet. Clinical measurements included height, weight, waist circumference, heart rate, blood pressure, and fasting blood sampling, with analyses of glucose, total cholesterol, HDL-cholesterol, LDL-cholesterol, and triglycerides.

Analysis of (co) variance was used to compare the Healthy Diet Score and its components between countries and sexes using baseline data, and to test differences in clinical characteristics between score categories, adjusted for age, sex and country. Pearson's correlations were used to study the association between changes from baseline to year 1 in the Healthy Diet Score and clinical markers. To estimate reproducibility, Pearson's correlations were studied between baseline and 1 year score, within the control group only.

Results: The mean total score was $52.8 \pm 12.8$ among women and $46.6 \pm 12.8$ among men $(p<0.001)$. The total score and its components differed between countries. The change in the Healthy Diet Score was significantly correlated with changes in BMI, waist circumference, and total and LDL cholesterol. The Healthy Diet Score as well as its components at baseline were significantly correlated with the values at year 1 , in the control group participants.

(Continued on next page)
\end{abstract}

\footnotetext{
* Correspondence: eeva.virtanen@thl.fi

'Department of Public Health Solutions, National Institute for Health and Welfare, PO BOX 30, 00270 Helsinki, Finland

Full list of author information is available at the end of the article
}

(c) The Author(s). 2020 Open Access This article is licensed under a Creative Commons Attribution 4.0 International License, which permits use, sharing, adaptation, distribution and reproduction in any medium or format, as long as you give appropriate credit to the original author(s) and the source, provide a link to the Creative Commons licence, and indicate if changes were made. The images or other third party material in this article are included in the article's Creative Commons licence, unless indicated otherwise in a credit line to the material. If material is not included in the article's Creative Commons licence and your intended use is not permitted by statutory regulation or exceeds the permitted use, you will need to obtain permission directly from the copyright holder. To view a copy of this licence, visit http://creativecommons.org/licenses/by/4.0/ The Creative Commons Public Domain Dedication waiver (http://creativecommons.org/publicdomain/zero/1.0/) applies to the data made available in this article, unless otherwise stated in a credit line to the data. 
(Continued from previous page)

Conclusion: The Feel4Diabetes Healthy Diet Score is a reproducible method to capture the dietary information collected with the Feel4Diabetes questionnaire and measure the level of and changes in the adherence to the dietary goals of the intervention. It gives a simple parameter that associates with clinical risk factors in a meaningful manner.

Trial registration: Clinicaltrials.gov NCT02393872. Registered March 20, 2015.

Keywords: Diet, Diet score, Evaluation, Intervention, Risk factors, Type 2 diabetes, Validity

\section{Background}

Type 2 diabetes (T2DM) is a chronic disease that develops as a result of interactions between genetic and environmental factors. In addition to obesity and sedentary lifestyle, the composition of the diet is recognized as one of the important modifiable factors in the development of T2DM [1]. Lifestyle interventions focusing on dietary modification and increasing physical activity have been shown to prevent the development of T2DM in people at high risk [2]. To evaluate the effectiveness of a preventive intervention, it is thus important to be able to measure the achieved changes in lifestyle using validated methods.

One of the aims in the multinational Feel4Diabetes project was to identify families at increased T2DM risk and provide them interventions to decrease the risk in a cluster-randomized study setting in 6 European countries (Belgium, Finland, Greece, Spain, Hungary, Bulgaria) [3]. The high-risk families living in the intervention areas were subject to the interventions delivered in the school and community setting between 2016 and 2018. In addition, they were offered a possibility to take part in a more intensive lifestyle counselling, consisting of group and individual sessions and SMS-intervention focusing specifically on preventing the development of T2DM.

To measure the effect of the Feel4Diabetes intervention on dietary behaviours, questions on dietary intake were included in the questionnaire which the parents filled in at baseline and after 1 and 2 years [3, 4]. The dietary questions were formulated to focus specifically on the intake of the food items that had been chosen as the goals in the Feel4Diabetes dietary intervention. To test the questionnaire reliability, a total of 191 parents completed the questionnaires twice, with a 1-2 week interval, and based on the intra-class correlation coefficients (ICC) of test-retest the developed questionnaires showed acceptable reliability [4]. Based on the dietary questions, the Feel4Diabetes Healthy Diet Score was compiled, in order to simplify the information from the questionnaire in a single parameter that can be used as a marker of dietary compliance.

The aim of this paper is to present the development of the Feel4Diabetes Healthy Diet Score and to evaluate its clinical validity.

\section{Methods}

\section{Study population and measurements}

Participants were 3268 adults (63\% women) from high diabetes risk families living in the Feel4Diabetes study areas in 6 European countries. A high-risk family was defined as at least one of the parents having (relatively) high score in the Finnish Diabetes Risk Score FINDRISC [5]. FINDRISC is a validated tool to identify people at risk of developing T2DM in the future, consisting of eight questions (age, body mass index (BMI), waist circumference, physical activity, consumption of fruit and vegetables, blood pressure medication, high blood glucose measured at any point, and family history of diabetes). The FINDRISC Score ranges from 0 to 26 , with score 12 or higher indicating increased T2DM risk. The mean age of the study participants was $42 \pm 7$ years, and $82 \%$ of them were married or lived with a spouse. The average years of education completed were 14-15 years, and $67 \%$ of the participants worked full or part-time during the intervention period. The recruitment of the participants, as well as the procedures and measurements, has been explained in detail earlier [3]. In brief, the adults who consented to take part in the clinical study were invited to a study visit. The measurements included height, weight, waist circumference, heart rate, blood pressure, and fasting blood sampling, with analyses of glucose, total cholesterol, HDL-cholesterol, LDL-cholesterol, and triglycerides. Body mass index (BMI) was calculated as weight $(\mathrm{kg})$ divided by height (m) squared. Waist-to-height ratio (WHtR) was calculated dividing waist circumference $(\mathrm{m})$ by height $(\mathrm{m})$. Participants also filled in a questionnaire including dietary questions, which were used to develop components of the Score (see Additional file 1). The measurements were repeated after 1 year.

\section{Feel4Diabetes healthy diet score}

Dietary goals set in Feel4Diabetes intervention were used as the basis for the Feel4Diabetes Healthy Diet Score. There were a total of 12 Feel4Diabetes intervention goals that were related to food choices or food behaviour, and were selected as the main components of the Healthy Diet Score (Table 1). These components were breakfast, vegetables, fruit and berries, sugary drinks, whole-grain 
Table 1 Scoring of the Healthy Diet Score

\begin{tabular}{ll}
\hline Component and F4D dietary goal & Content \\
\hline $\begin{array}{l}\text { Eating (healthy and balanced) breakfast } \\
\text { daily }\end{array}$ & Weekdays and weekend days \\
& \\
& \\
2. Vegetables & Raw and cooked vegetables, \\
$\geq 5$ servings of vegetable per day & cooked legumes
\end{tabular}

3. Fruits and berries

$\geq 3$ servings of fruit \& berries per day

4. Sugary drinks

$<1$ serving of sugary drinks per day

5. Whole-grain cereals

$\geq 4$ servings of whole-grain foods/cereals per day

6. Nuts and Seeds

$\geq 3$ servings of nuts \& seeds a week

7. Low-fat Dairy

$\geq 1$ serving of low-fat dairy products per day

8. Oils and fats

daily use of olive or rapeseed oil or soft margarine including cooking fats and spreads

Favorable fats: dressings

\begin{tabular}{|c|c|}
\hline Categories & Score \\
\hline 5 times on weekdays & 7 \\
\hline 3-4 times on weekdays & 4 \\
\hline $1-2$ times on weekdays & 1 \\
\hline I don't eat breakfast & 0 \\
\hline 2 times during weekend & 3 \\
\hline 1 time during weekend & 2 \\
\hline I don't eat breakfast & 0 \\
\hline Total score & 10 \\
\hline 5 servings per day & 10 \\
\hline 4 servings per day & 8 \\
\hline 3 servings per day & 6 \\
\hline 2 servings per day & 4 \\
\hline 1 servings per day & 2 \\
\hline$<1$ serving per day & 0 \\
\hline 3 or more servings per day & 10 \\
\hline $1-2$ servings per day & 8 \\
\hline 5-6 servings per week & 6 \\
\hline 3-4 servings per week & 4 \\
\hline $1-2$ servings per week & 2 \\
\hline$<1$ serving per week & 0 \\
\hline$<1$ serving per day & 10 \\
\hline $1-2$ servings per day & 8 \\
\hline 3-4 servings per day & 6 \\
\hline 5-6 servings per day & 4 \\
\hline$\geq 7$ servings per day & 0 \\
\hline$\geq 4$ servings per day & 10 \\
\hline 3 servings per day & 7 \\
\hline 2 servings per day & 4 \\
\hline 1 serving per day & 1 \\
\hline$<1$ serving per day & 0 \\
\hline$\geq 3$ servings per week & 6 \\
\hline $1-2$ servings per week & 3 \\
\hline$<1$ time per week & 0 \\
\hline$\geq 1$ servings per day and no full-fat dairy products & 6 \\
\hline $\begin{array}{l}\geq 1 \text { servings per day and } \geq 1 \text { servings of full-fat dairy } \\
\text { products }\end{array}$ & 3 \\
\hline $\begin{array}{l}<1 \text { serving per day and } \leq 1 \text { servings of full-fat dairy } \\
\text { products }\end{array}$ & 0 \\
\hline Cooking (option to choose several): & \\
\hline
\end{tabular}
vegetable oils, margarine, soft and reduced-fat margarine, oil based

Avoidable fats:

butter, butter mixtures, I don't use any
Daily use of vegetable oils and margarines and no use 4 of butter

Daily use of vegetable oils and margarines and some 2 usage of butter

Daily use or no usage of vegetable oils or margarines 0 and higher usage of butter or no usage of daily fats

Bread spreads (option to choose only one): 
Table 1 Scoring of the Healthy Diet Score (Continued)

\begin{tabular}{|c|c|c|c|}
\hline Component and F4D dietary goal & Content & Categories & Score \\
\hline & & $\begin{array}{l}\text { Daily use of vegetable oil, Soft margarine } 70-80 \% \\
\text { or fat }\end{array}$ & 0 \\
\hline & & Reduced-fat margarine $28-60 \%$ fat & \\
\hline & & $\begin{array}{l}\text { Daily use of butter-vegetable oil mixture, butter } \\
\text { or I do not use fat spread on bread }\end{array}$ & 8 \\
\hline & & Total score & \\
\hline \multirow{6}{*}{$\begin{array}{l}\text { 9. Red meat } \\
\leq 2 \text { servings of red and/or processed } \\
\text { meat a week }\end{array}$} & \multirow[t]{6}{*}{ Red and processed meat } & $\leq 2$ servings per week & 10 \\
\hline & & 3 servings per week & 8 \\
\hline & & 4 servings per week & 6 \\
\hline & & 5 servings per week & 4 \\
\hline & & 6 servings per week & 2 \\
\hline & & $\geq 7$ servings per week & 0 \\
\hline \multirow{5}{*}{$\begin{array}{l}\text { 10. Sweet snacks } \\
\leq 1 \text { serving of sweet snacks per week }\end{array}$} & \multirow[t]{5}{*}{ Biscuits, ice cream, cakes, pastries etc. } & $\leq 1$ servings per week & 6 \\
\hline & & 2 servings per week & 5 \\
\hline & & 3-4 servings per week & 3 \\
\hline & & $5-6$ servings per week & 1 \\
\hline & & $\geq 1$ servings per day & 0 \\
\hline \multirow{5}{*}{$\begin{array}{l}\text { 11. Salty snacks } \\
\leq 1 \text { serving of salty snacks/fast food } \\
\text { per week }\end{array}$} & \multirow{5}{*}{$\begin{array}{l}\text { Hamburger, chips, pizza, savory pastries } \\
\text { etc. }\end{array}$} & $\leq 1$ servings per week & 6 \\
\hline & & 2 servings per week & 5 \\
\hline & & 3-4 servings per week & 3 \\
\hline & & $5-6$ servings per week & 1 \\
\hline & & $\geq 1$ servings per day & 0 \\
\hline \multirow{13}{*}{$\begin{array}{l}\text { 12. Family meals } \\
\text { Meals eaten with others }\end{array}$} & \multirow{13}{*}{$\begin{array}{l}\text { Breakfast, lunch and dinner with a friend, } \\
\text { colleague, or with a family member }\end{array}$} & Breakfast & \\
\hline & & $\geq 7$ times per week & 2 \\
\hline & & 5-6 times per week & 1 \\
\hline & & $\leq 4$ times per week & 0 \\
\hline & & Lunch & \\
\hline & & $\geq 7$ times per week & 2 \\
\hline & & 5-6 times per week & 1 \\
\hline & & $\leq 4$ times per week & 0 \\
\hline & & Dinner & \\
\hline & & $\geq 7$ times per week & 4 \\
\hline & & 5-6 times per week & 2 \\
\hline & & $\leq 4$ times per week & 0 \\
\hline & & Total score & $0-8$ \\
\hline Total Healthy Diet Score & \multicolumn{2}{|l|}{ All components (1-12) } & $\begin{array}{l}0- \\
100\end{array}$ \\
\hline
\end{tabular}

cereals, nuts and seeds, low-fat dairy products, oils and fats, red meat, sweet snacks, salty snacks, and family meals. Excluded intervention goals were related to physical activity and sedentary behaviour, and thus not included as part of the Healthy Diet Score.

Scoring of the components was done according to the 14 diet-related questions in the Feel4Diabetes questionnaire. Each component reflected one or two questions about intake frequencies of each particular food group or food behaviour. Components consisting of two questions were vegetables and oils and fats. Vegetables included questions about vegetable and legume consumption, and oils and fats included questions about bread spreads and daily use of different oils and fats. The maximum score for each component was set based on its estimated relative importance with regards to T2DM risk. A maximum score of 10 was given to breakfast, vegetables, fruit and berries, sugary drinks 
(including juices and soft drinks containing sugar and also high energy beverages beer, cider, wine and spirits), whole-grain cereals, and red meat. A maximum score of 8 was given to the consumption of oils and fats and frequency of family meals (including breakfast, lunch and dinner eaten in the company of others, defined as a friend, colleague or family member). The rest of the components, sweet snacks, salty snacks, nuts and seeds, and low-fat dairy, got a maximum score of 6 . A higher score indicated higher or more frequent consumption, except for sugary drinks, red meat, sweet snacks and salty snacks where higher scores indicated lower consumption. Total score, calculated as the sum of the component scores, was ranging from 0 to 100 , higher score indicating better quality of diet and maximum score indicating full achievement of the Feel4Diabetes dietary goals.

\section{Descriptive and statistical analyses}

Data was analyzed with IBM SPSS Statistics for Windows Version 25.0. The Healthy Diet Score components were calculated for each country and men and women separately using baseline data. Score component values, as country means for men and women, are presented as bar charts. The Feel4Diabetes Healthy Diet Score was divided into quarters. A multivariate analysis of covariance was used to test differences in clinical characteristics between the Score categories. In the model, clinical characteristics were used as dependent variables and score categories as the independent variable. The model was adjusted for age, sex and country and results are presented as marginal estimated means, standard deviations, and $p$-values.

To estimate the clinical validity of the Feel4Diabetes Healthy Diet Score, the changes in the Score and changes in clinical markers between baseline and first year follow-up were studied using Pearson's correlation. To estimate reproducibility, Pearson's correlations were studied between baseline and first year follow-up scores within the control group participants only. Results from both analyses using Pearson's correlation are presented as correlation coefficients and $p$-values.

\section{Results}

The distribution of the Healthy Diet Score in the total population at the baseline is depicted in Fig. 1.

The mean total score was $52.8 \pm 12.8$ among women and $46.6 \pm 12.8$ among men $(p<0.001)$. The mean score values by sex and country are presented in Fig. 2 . There were significant differences in the total score, as well as its components, between countries.

The total score was highest among Finnish (56.8 \pm 11.9) and Spanish (52.9 \pm 11.4$)$, and lowest in Hungarian $(47.8 \pm 12.7)$ and Bulgarian $(47.9 \pm 11.5)$ adults. Of the components, score value was generally low for vegetables and high for salty snacks and breakfast.

The baseline clinical characteristics of all study participants according to Healthy Diet Score, adjusted for age, sex and country are presented in Table 2 . The Score was directly associated with HDL-cholesterol $(p=0.022)$, and inversely associated with LDL-cholesterol $(p=0.003)$ and triglyceride $(p=0.043)$ concentrations as well as heart rate $(p=0.012)$.

The change in Healthy Diet Score from baseline to year 1 , amongst all participants, was significantly and inversely correlated with changes in BMI, waist circumference, waistto-height ratio and total and LDL cholesterol (Table 3). Increase in component scores for vegetables, fruit and berries, sweet snacks, salty snacks, and red meat correlated with a decrease of body weight indices, and increased intake of vegetables also with a decrease of total cholesterol and triglycerides. Higher consumption of whole-grains correlated

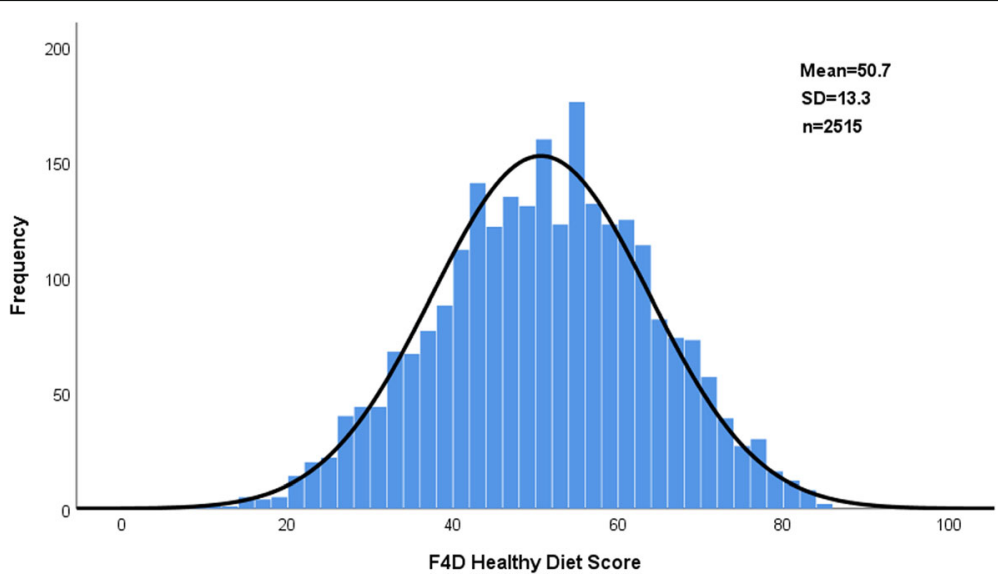

Fig. 1 Distribution of the Healthy Diet Score in study population 


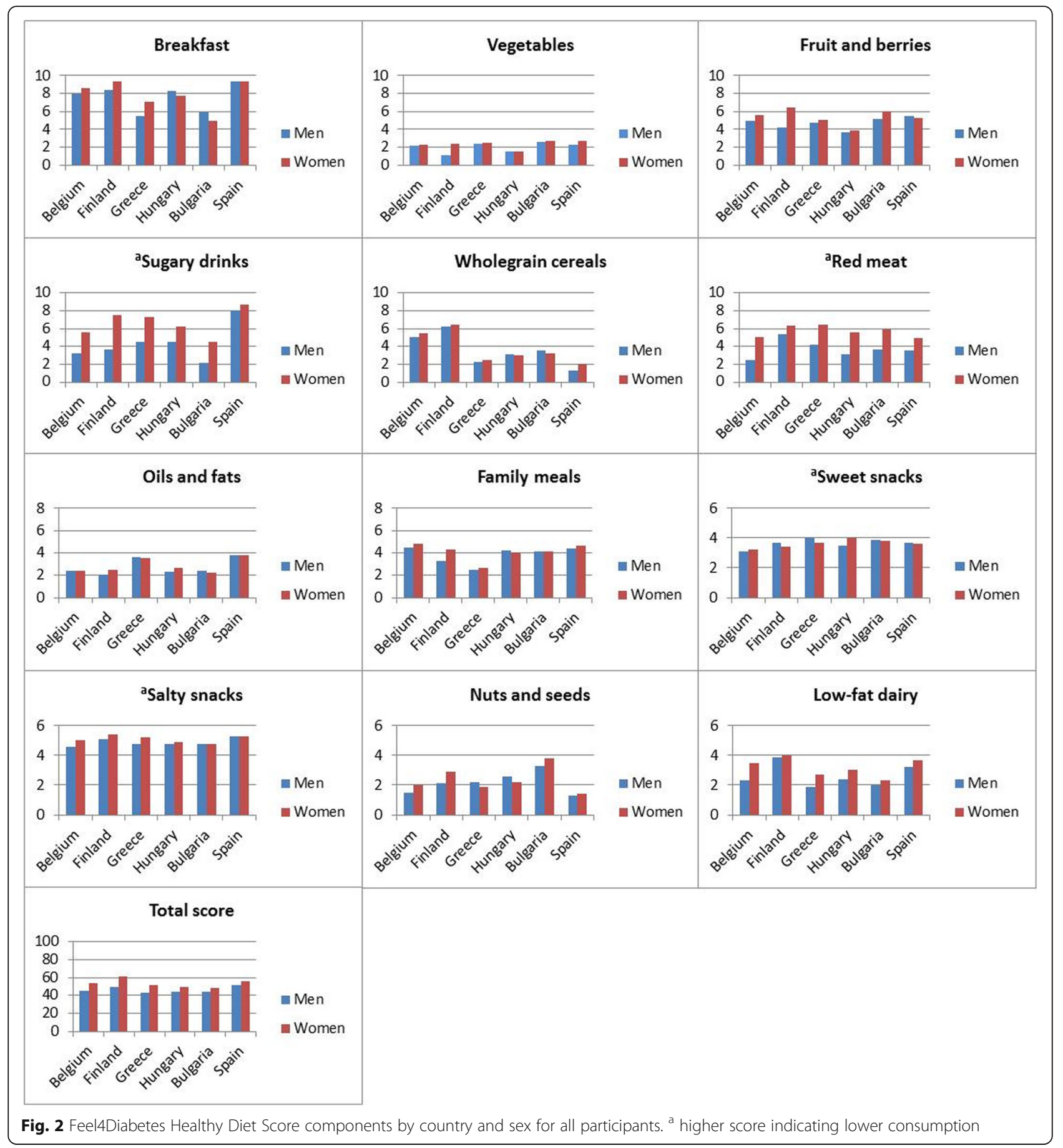

only with a decrease of total and LDL-cholesterol. Improvement in breakfast habits correlated with a reduction in BMI, but improvement in family meal practices did not correlate with any clinical changes. Sugary drinks correlated only with a change in systolic blood pressure, but the correlation was not in the expected direction. Also for the change in sweet and salty snacks score components an inverse correlation with HDL-cholesterol was discovered.
The Healthy Diet Score, as well as its components at baseline, were significantly correlated with the values at year 1 in the analysis including only the control group participants (Table 4). The Correlation coefficients varied from $0.479(p<0.001)$ for fats and oils to 0.795 $(p<0.001)$ for breakfast. For the total score, the correlation coefficient between baseline and year 1 was 0.755 $(p<0.001)$. 
Table 2 Baseline clinical characteristics of all participants by Healthy Diet Score quarters (EMM, SE and ANCOVA p-value)

\begin{tabular}{|c|c|c|c|c|c|}
\hline & 1. quarter $0-42$ & 2. quarter $43-51$ & 3. quarter $52-60$ & 4. quarter $61-100$ & $p$-value \\
\hline BMI $\left(\mathrm{Kg} / \mathrm{m}^{2}\right)$ & $28.9 \pm 0.2$ & $28.7 \pm 0.2$ & $28.1 \pm 0.2$ & $28.2 \pm 0.2$ & 0.054 \\
\hline Waist circumference $(\mathrm{cm})$ & $95.3 \pm 0.5$ & $95.0 \pm 0.6$ & $94.0 \pm 0.5$ & $94.4 \pm 0.6$ & 0.325 \\
\hline WHtR & $0.57 \pm 0.0$ & $0.57 \pm 0.0$ & $0.56 \pm 0.0$ & $0.56 \pm 0.0$ & 0.113 \\
\hline SBP $(\mathrm{mmHg})$ & $118 \pm 1$ & $119 \pm 1$ & $118 \pm 1$ & $119 \pm 1$ & 0.779 \\
\hline $\mathrm{DBP}(\mathrm{mmHg})$ & $79 \pm 1$ & $79 \pm 1$ & $79 \pm 1$ & $79 \pm 1$ & 0.882 \\
\hline Heart rate (bpm) & $73 \pm 0$ & $72 \pm 0$ & $72 \pm 0$ & $71 \pm 0$ & $0.012^{*}$ \\
\hline total Cholesterol (mmol/L) & $5.12 \pm 0.04$ & $5.02 \pm 0.04$ & $5.03 \pm 0.04$ & $4.96 \pm 0.04$ & 0.058 \\
\hline LDL-cholesterol (mmol/L) & $3.21 \pm 0.04$ & $3.10 \pm 0.04$ & $3.10 \pm 0.04$ & $3.02 \pm 0.04$ & $0.003^{*}$ \\
\hline HDL-cholesterol (mmolL) & $1.36 \pm 0.04$ & $1.36 \pm 0.04$ & $1.38 \pm 0.04$ & $1.42 \pm 0.04$ & $0.022^{*}$ \\
\hline TG (mg/dL) & $1.29 \pm 0.04$ & $1.31 \pm 0.03$ & $1.23 \pm 0.03$ & $1.17 \pm 0.04$ & $0.043^{*}$ \\
\hline Glucose (mmol/L) & $5.24 \pm 0.04$ & $5.33 \pm 0.05$ & $5.31 \pm 0.05$ & $5.37 \pm 0.05$ & 0.240 \\
\hline
\end{tabular}

${ }^{*} p<0.05$, ANCOVA adjusted for age, sex and country. BMI Body mass index, WHtR Waist-to-Height ratio, SBP Systolic blood pressure, DBP Diastolic blood pressure, TG Triglycerides, EMM Estimated marginal means, SE Standard error

\section{Discussion}

In this paper, we report the construction of the Feel4Diabetes Healthy Diet Score and present some findings to support its usability, reproducibility and clinical validity. The Healthy Diet Score is constructed based on the questionnaire that was developed for the Feel4Diabetes project [4]. A detailed description of the study population and design, as well as study results, are out of the scope of this paper.

The Healthy Diet Score was created to standardize and simplify the Feel4Diabetes dietary questionnaire [4] data in a single parameter that allows rapid evaluation of the diet across this multi-national project. The Healthy Diet Score is comprised of components that represent the dietary goals of the Feel4Diabetes high-risk intervention, weighted based on their appraised importance as risk or protective factors for type 2 diabetes.

The weights of the components were decided based on research literature. The most convincing evidence about the potential of dietary manipulation in reducing T2DM risk comes from randomized prevention trials. The Finnish Diabetes Prevention Study (DPS) was the first individually-randomized controlled trial to show that T2DM can be prevented by dietary and physical activity counselling [6]. Risk of developing T2DM was shown to be the lowest among the participants who consumed a diet with moderate fat and high fibre content [7]. In the Diabetes Prevention Program, another important trial

Table 3 Pearson's correlation for changes in the Healthy Diet Score components and clinical markers between baseline and first year for all participants

\begin{tabular}{|c|c|c|c|c|c|c|c|c|c|c|c|}
\hline & $\begin{array}{l}\mathrm{BMI} \\
\left(\mathrm{kg} / \mathrm{m}^{2}\right)\end{array}$ & $W C(\mathrm{~cm})$ & $\mathrm{WH} \mathrm{tR}$ & $\begin{array}{l}\text { SBP } \\
(\mathrm{mmHg})\end{array}$ & $\begin{array}{l}\text { DBP } \\
(\mathrm{mmHg})\end{array}$ & $\begin{array}{l}\text { Heart rate } \\
(\mathrm{bpm})\end{array}$ & $\begin{array}{l}\mathrm{TC} \\
(\mathrm{mmol} / \mathrm{l})\end{array}$ & $\begin{array}{l}\mathrm{LDL} \\
(\mathrm{mmol} / \mathrm{l})\end{array}$ & $\begin{array}{l}\mathrm{HDL} \\
(\mathrm{mmol} / \mathrm{l})\end{array}$ & $\begin{array}{l}\text { Glucose } \\
(\mathrm{mmol} / \mathrm{l})\end{array}$ & $\begin{array}{l}\text { TG } \\
(\mathrm{mmol} / \mathrm{l})\end{array}$ \\
\hline Total score & $-0.143^{* *}$ & $-0.116^{* *}$ & $-0.123^{* *}$ & ns & ns & ns & $-0.127^{* *}$ & $-0.114^{* *}$ & ns & ns & ns \\
\hline Breakfast & $-0.061^{*}$ & ns & ns & ns & ns & ns & ns & ns & ns & ns & ns \\
\hline Vegetables & $-0.077^{* *}$ & $-0.080^{* *}$ & $-0.070^{* *}$ & ns & ns & ns & $-0.052^{*}$ & ns & ns & ns & $-0.050^{*}$ \\
\hline Fruit and berries & $-0.064^{*}$ & $-0.069^{* *}$ & $-0.061^{*}$ & ns & ns & ns & ns & ns & ns & ns & ns \\
\hline Sugary drinks & ns & ns & ns & $0.053^{*}$ & ns & ns & ns & ns & ns & ns & ns \\
\hline Whole-grain & ns & ns & ns & ns & ns & ns & $-0.065^{*}$ & $-0.062^{*}$ & ns & ns & ns \\
\hline Nuts and seeds & ns & $-0.052^{*}$ & $-0.052^{*}$ & ns & ns & ns & ns & ns & ns & ns & ns \\
\hline Low-fat dairy & ns & ns & ns & ns & ns & ns & ns & ns & ns & ns & ns \\
\hline Oils and fats & $-0.052^{*}$ & ns & ns & ns & ns & ns & ns & ns & ns & ns & ns \\
\hline Red meat & $-0.089^{* *}$ & $-0.077^{* *}$ & $-0.078^{* *}$ & ns & ns & ns & ns & ns & ns & ns & ns \\
\hline Sweet snacks & $-0.120^{* *}$ & $-0.098^{* *}$ & $-0.103^{* *}$ & ns & ns & ns & ns & ns & $-0.061^{*}$ & ns & ns \\
\hline Salty snacks & $-0.061^{*}$ & $-0.073^{* *}$ & $-0.070^{* *}$ & ns & ns & ns & ns & ns & $-0.058^{*}$ & ns & ns \\
\hline Family meals & ns & ns & ns & ns & ns & ns & ns & ns & ns & ns & ns \\
\hline
\end{tabular}

${ }^{*} p<0.05$ and ${ }^{* *} p<0.01$. ns non-significant

$B M I$ Body mass index, WC Waist circumference, WHtR Waist-to-Height ratio, SBP Systolic blood pressure, DBP Diastolic blood pressure, $T C$ total cholesterol, $L D L$ LDL-cholesterol, HDL HDL-cholesterol, TG Triglycerides 
Table 4 Correlation for the Healthy Diet Score components between baseline and first year for controls

\begin{tabular}{lll}
\hline Score component & Pearson's correlation & $p$-value \\
\hline Total Score & $0.755^{* *}$ & $<0.001$ \\
Breakfast & $0.795^{* *}$ & $<0.001$ \\
Vegetables & $0.486^{* *}$ & $<0.001$ \\
Fruit and berries & $0.704^{* *}$ & $<0.001$ \\
Sugary drinks & $0.622^{* *}$ & $<0.001$ \\
Whole-grain cereals & $0.565^{* *}$ & $<0.001$ \\
Nuts and seeds & $0.602^{* *}$ & $<0.001$ \\
Low-fat dairy & $0.517^{* *}$ & $<0.001$ \\
Oils and fats & $0.479^{* *}$ & $<0.001$ \\
Red meat & $0.626^{* *}$ & $<0.001$ \\
Sweet snacks & $0.624^{* *}$ & $<0.001$ \\
Salty snacks & $0.558^{* *}$ & $<0.001$ \\
Family meals & $0.616^{* *}$ & $<0.001$ \\
\hline ** $p<0.01$ & &
\end{tabular}

showing the effectiveness of lifestyle intervention in T2DM prevention, the diet was focused on the reduction of total fat and energy [8]. However, as we wanted the Feel4Diabetes Healthy Diet Score to be based on food rather than nutrient intake, research evidence from dietary patterns $[1,9]$ and other observational studies [10-15] were also considered when the scoring for the components was created.

Furthermore, we wanted the score to be sensitive for all beneficial changes in diet, e.g. increase in consumption of fruit from once per day to twice per day, even if the actual goal (three portions per day) is not achieved. This approach differs from the one used in many studies. For example in the DPS, the "success score" varied from 0 to 5 , according to the number of intervention goals (total fat intake $<30 \%$ of total energy consumed, saturated fat $<10 \%$ of total energy, and dietary fibre 15 $\mathrm{g} / 1000 \mathrm{kcal}$ or more, physical activity $30 \mathrm{~min}$ per day, weight reduction 5\% from baseline) [6]. Another example is the PREDIMED study, where the Mediterranean diet score was calculated as the sum of dichotomized goals [16]. In real-life implementation projects, achieved changes in diet are often smaller than in clinical trials. In fact, it is generally acknowledged that setting small, achievable short term goals, as well as focusing on gradually building on behaviours that already are familiar, increases the likelihood that the new way of eating becomes a permanent habit [17]. For the Feel4Diabetes Healthy Diet Score, we wanted to acknowledge all the changes in diet, even when the actual intervention goal was not achieved. The score was composed from all the relevant information available in the validated questionnaire, and all changes for the better increased the score.
The Healthy Diet Score at baseline was normally distributed and thus demonstrated variation within the study population. However, the country means of the Score, as well as its components, differed significantly from each other. These differences appeared plausible, considering the differing dietary cultures in the participating countries $[18,19]$. For example, in Finland whole grain rye bread and low-fat milk are staples, and this is also reflected in the Score components for whole-grain cereal and dairy products. The consumption of vegetables was much lower than recommended across the countries, clearly indicating a need for public health actions to tackle the problem.

In the cross-sectional analysis, the Feel4Diabetes Healthy Diet Score category was significantly, albeit moderately associated with clinical risk factors such as HDL- and LDL-cholesterol and triglycerides, when age, sex, and country were adjusted for. There also appeared to be a trend between decreasing BMI and increasing score. This association did not reach statistical significance. In the analysis exploring the association between changes in the Score and its components as opposed to changes in clinical risk factors, several associations were discovered. These analyses combined offer proof for the clinical validity of our Healthy Diet Score. Many diet scores have been developed for different purposes, and they have been proved clinically useful, especially when combined with other non-invasive measurements of risk factors [20]. Lassale et al. who compared the performance of different scores advocate the use of easy-tomeasure, concise food-based scores that are developed based on predefined rather than study population-based cut-off points and propose that such scores "would be most pragmatic for individual risk prediction and health promotion" [20]. This is indeed also our justification for the development of the Feel4Diabetes Healthy Diet Score.

Finally, the reproducibility of the Healthy Diet Score was shown to be good, based on the analysis of correlation between baseline and 1 year score components in the control participants only. This analysis excluded intervention subjects, as they were, by definition, instructed on how to make beneficial changes in their diet.

An important limitation of the present study is that we do not have a reference method (e.g. food diaries) for dietary data collection. However, the questionnaire reliability was tested in volunteers in each country before the study [4] and was shown to be acceptable.

\section{Conclusions}

The Feel4Diabetes Healthy Diet Score is a reproducible method to capture the dietary information collected with the Feel4Diabetes questionnaire and measure the level of 
and changes in the adherence to the dietary goals of the intervention. It gives a simple parameter that associates with clinical risk factors in a meaningful and plausible manner. The Healthy Diet Score was constructed to facilitate the analyses of the Feel4Diabetes study outcomes, but it could also serve as a simple and visual tool to measure dietary intake in e.g. health care services and public health initiatives.

\section{Supplementary information}

Supplementary information accompanies this paper at https://doi.org/10. 1186/s12902-020-0521-X.

Additional file 1. Feel4Diabetes dietary questions used in the

development of the Healthy Diet score.

\section{Abbreviations}

BMI: Body mass index; DPS: Diabetes Prevention Study; FINDRISC: Finnish Diabetes Risk Score; HDL: High-density lipoprotein; LDL: Low-density lipoprotein; T2DM: Type 2 diabetes mellitus

\section{Acknowledgements}

The authors would like to thank all families participated and the members of the Feel4Diabetes-study Group:

Coordinator: Yannis Manios.

Steering Committee: Yannis Manios, Greet Cardon, Jaana Lindström, Peter Schwarz, Konstantinos Makrilakis, Lieven Annemans, Ignacio Garamendi. Harokopio University (Greece).

Yannis Manios, Kalliopi Karatzi, Odysseas Androutsos, George Moschonis, Spyridon Kanellakis, Christina Mavrogianni, Konstantina Tsoutsoulopoulou, Christina Katsarou, Eva Karaglani, Irini Qira, Efstathios Skoufas, Konstantina Maragkopoulou, Antigone Tsiafitsa, Irini Sotiropoulou, Michalis Tsolakos, Effie Argyri, Mary Nikolaou, Eleni-Anna Vampouli, Christina Filippou, Kyriaki Apergi, Amalia Filippou, Gatsiou Katerina, Efstratios Dimitriadis.

National Institute for Health and Welfare (Finland).

Jaana Lindström, Tiina Laatikainen, Katja Wikström, Jemina Kivelä, Päivi Valve, Esko Levälahti, Eeva Virtanen, Tiina Pennanen, Seija Olli, Karoliina Nelimarkka. Ghent University (Belgium).

Department of Movement and Sports Sciences: Greet Cardon, Vicky Van Stappen, Nele Huys.

Department of Public Health: Lieven Annemans, Ruben Willems. Department of Endocrinology and Metabolic Diseases: Samyah Shadid. Technische Universität Dresden (Germany).

Peter Schwarz, Patrick Timpel.

University of Athens (Greece).

Konstantinos Makrilakis, Stavros Liatis, George Dafoulas, Christina-Paulina Lambrinou, Angeliki Giannopoulou.

International Diabetes Federation European Region (Belgium).

Lala Rabemananjara, Maria Stella de Sabata, Winne Ko, Ignacio Garamendi. Universidad De Zaragoza (Spain).

Luis Moreno, Fernando Civeira, Gloria Bueno, Pilar De Miguel-Etayo, Esther Ma Gonzalez-Gil, María L. Miguel-Berges, Natalia Giménez-Legarre; Paloma Flores-Barrantes, Aleli M. Ayala-Marín, Miguel Seral-Cortés, Lucia Baila-Rueda, Ana Cenarro, Estíbaliz Jarauta, Rocío Mateo-Gallego. Medical University of Varna (Bulgaria).

Violeta lotova, Tsvetalina Tankova, Natalia Usheva, Kaloyan Tsochev, Nevena Chakarova, Sonya Galcheva, Rumyana Dimova, Yana Bocheva, Zhaneta Radkova, Vanya Marinova, Yuliya Bazdarska, Tanya Stefanova.

University of Debrecen (Hungary).

Imre Rurik, Timea Ungvari, Zoltán Jancsó, Anna Nánási, László Kolozsvári,

Csilla Semánova, Éva Bíró, Emese Antal, Sándorné Radó.

Extensive Life Oy (Finland).

Remberto Martinez, Marcos Tong.

\section{About this supplement}

This article has been published as part of BMC Endocrine Disorders, Volume 20 Supplement 2, 2020: Designing, implementing and evaluating a community- based intervention to prevent diabetes in vulnerable families across Europe. The Feel4Diabetes-study. The full contents of the supplement are available at https://bmcendocrdisord.biomedcentral.com/articles/supplements/volume-20supplement-2.

\section{Authors' contributions}

$\mathrm{EV}, \mathrm{JK}, \mathrm{KW}$ and $\mathrm{JL}$ constructed the Healthy Diet Score and designed the study. EV conducted the statistical analyses. EV and $J \mathrm{~L}$ wrote the firsts draft of the manuscript. JK, KW, CPL, YM, SL, KM, CG, NH, VI, NU, NC, SAR, KVT, $L A M, P D M E$, and $J L$ critically revised the manuscript and read and approved the final manuscript. The authors read and approved the final manuscript.

\section{Funding}

The publication of this supplement was funded by Feel4Diabetes study. The Feel4Diabetes-study has received funding from the European Union's Horizon 2020 research and innovation programme under grant agreement $n^{\circ}$ 643708. The content of this article reflects only the authors' views and the European Community is not liable for any use that may be made of the information contained therein

\section{Availability of data and materials \\ Not applicable.}

\section{Ethics approval and consent to participate}

This study was conducted according to the guidelines laid down in the Declaration of Helsinki and all procedures involving human subjects were approved by the ethics committees in all countries (in Belgium, by the Medical Ethics Committee of the Ghent University Hospital; in Bulgaria, by the Ethics Committee of the Medical University of Varna; in Finland, by the hospital district of Southwest Finland ethical committee; in Greece, by the Bioethics Committee of Harokopio University; in Hungary, by the National Committee for Scientific Research in Medicine; in Spain, by the Clinical Research Ethics Committee). Written informed consent was obtained from all subjects.

\section{Consent for publication}

Not applicable.

\section{Competing interests}

The authors declare that they have no competing interests.

\section{Author details}

'Department of Public Health Solutions, National Institute for Health and Welfare, PO BOX 30, 00270 Helsinki, Finland. ${ }^{2}$ Department of Obstetrics and Gynecology, University of Helsinki and Helsinki University Hospital, Helsinki, Finland. Institute of Public Health and Clinical Nutrition, University of Eastern Finland, Kuopio, Finland. ${ }^{4}$ Department of Nutrition and Dietetics, Harokopio University, Athens, Greece. ${ }^{5}$ Growth, Exercise, Nutrition and Development Research Group, University of Zaragoza, GENUD, Zaragoza, Spain. ${ }^{6}$ Department of Movement and Sports Sciences, Ghent University, Ghent, Belgium. ${ }^{7}$ Debreceni Egyetem (UoD), University of Debrecen, Debrecen, Hungary. ${ }^{8}$ Department of Social Sciences and Public Health, Medical University of Varna, Varna, Bulgaria. ${ }^{9}$ Department of Diabetology, Clinical Center of Endocrinology, Medical University of Sofia, Sofia, Bulgaria.

${ }^{10}$ Department of Pediatrics, Clinic of Paediatric Endocrinology, Medical University Varna, Varna, Bulgaria. ${ }^{11}$ National and Kapodistrian University of Athens, Athens, Greece.

Received: 2 March 2020 Accepted: 5 March 2020 Published: 6 May 2020

\section{References}

1. Jannasch F, Kröger J, Schulze MB. Dietary patterns and type 2 diabetes: a systematic literature review and meta-analysis of prospective studies. J Nutr. 2017:147(6):1174-82

2. Hemmingsen B, Gimenez-Perez G, Mauricio D, Roqué I, Figuls M, Metzendorf Ml, Richter B. Diet, physical activity or both for prevention or delay of type 2 diabetes mellitus and its associated complications in people at increased risk of developing type 2 diabetes mellitus. Cochrane Database Syst Rev. 2017;12:CD003054. 
3. Manios $Y$, Androutsos $O$, Lambrinou CP, Cardon G, Lindström J, Annemans L, Mateo-Gallego R, de Sabata MS, lotova V, Kivelä J, Martinez R, Moreno LA, Rurik I, Schwarz P, Tankova T, Liatis S, Makrilakis K. A school- and community-based intervention to promote healthy lifestyle and prevent type 2 diabetes in vulnerable families across Europe: design and implementation of the Feel4Diabetes-study. Public Health Nutr. 2018;21(17): 3281-90.

4. Anastasiou C, Fappa E, Zachari K, Mavrogianni C, Van Stappen V, Kivelä J, Virtanen E, Gonzales-Gil E, Flores-Barrantes P, Nanasi A, Semanova C, Dimova R, Usheva N, lotova V, Cardong G, Manios Y, Makrilakis K, Feel4Diabetes study group. Development and reliability of questionnaires for the assessment of diet and physical activity behaviors in a multi-country sample in Europe: the Feel4Diabetes Study. BMC Suppl. 2020;20(Suppl 1): 135.

5. Lindström J, Tuomilehto J. The diabetes risk score: a practical tool to predict type 2 diabetes risk. Diabetes Care. 2003;26(3):725-31.

6. Tuomilehto J, Lindström J, Eriksson JG, Valle TT, Hämäläinen $H$, llanneParikka P, Keinänen-Kiukaanniemi S, Laakso M, Louheranta A, Rastas M, Salminen V, Uusitupa M. Prevention of type 2 diabetes mellitus by changes in lifestyle among subjects with impaired glucose tolerance. N Engl J Med. 2001;344(18):1343-50.

7. Lindström J, Peltonen M, Eriksson JG, Louheranta A, Fogelholm M, Uusitupa M, Tuomilehto J. High-fibre, low-fat diet predicts long-term weight loss and decreased type 2 diabetes risk: the Finnish diabetes prevention study. Diabetologia. 2006;49(5):912-20.

8. The Diabetes Prevention Program Research Group. The diabetes prevention program (DPP): description of lifestyle intervention. Diabetes Care. 2002; 25(12):2165-71.

9. Galbete C, Kroger J, Jannasch F, lqbal K, Schwingshackl L, Schwedhelm C, Weikert C, Boeing H, Schulze MB. Nordic diet, Mediterranean diet, and the risk of chronic diseases: the EPIC-Potsdam study. BMC Med. 2018;16(1):99.

10. Becerra-Tomás N, Díaz-López A, Rosique-Esteban N, Ros E, Buil-Cosiales P, Corella D, Estruch R, Fitó M, Serra-Majem L, Arós F, Lamuela-Raventós RM, Fiol M, Santos-Lozano JM, Díez-Espino J, Portoles O, Salas-Salvadó J, PREDIMED Study Investigators. Legume consumption is inversely associated with type 2 diabetes incidence in adults: a prospective assessment from the PREDIMED study. Clin Nutr. 2018;37(3):906-13.

11. Della Pepa G, Vetrani C, Vitale M, Riccardi G. Wholegrain intake and risk of type 2 diabetes: evidence from epidemiological and intervention studies. Nutrients. 2018;10(9):1288.

12. Guasch-Ferré M, Becerra-Tomás N, Ruiz-Canela M, Corella $D$, Schröder $H$, Estruch R, Ros E, Arós F, Gómez-Gracia E, Fiol M, Serra-Majem L, Lapetra J, Basora J, Martín-Calvo N, Portoles O, Fitó M, Hu FB, Forga L, Salas-Salvadó J. Total and subtypes of dietary fat intake and risk of type 2 diabetes mellitus in the Prevención con Dieta Mediterránea (PREDIMED) study. Am J Clin Nutr. 2017;105(3):723-35.

13. Malik VS, Popkin BM, Bray GA, Després JP, Willett WC, Hu FB. Sugarsweetened beverages and risk of metabolic syndrome and type 2 diabetes: a meta-analysis. Diabetes Care. 2010;33(11):2477-83.

14. Yu E, Hu FB. Dairy products, dairy fatty acids, and the prevention of Cardiometabolic disease: a review of recent evidence. Curr Atheroscler Rep. 2018;20(5):24

15. Schwingshackl L, Hoffmann G, Lampousi AM, Knüppel S, lqbal K, Schwedhelm C, Bechthold A, Schlesinger S, Boeing H. Food groups and risk of type 2 diabetes mellitus: a systematic review and meta-analysis of prospective studies. Eur J Epidemiol. 2017;32(5):363-75.

16. Salas-Salvadó J, Bulló M, Babio N, Martínez-González MÁ, Ibarrola-Jurado N, Basora J, Estruch R, Covas Ml, Corella D, Arós F, Ruiz-Gutiérrez V, Ros E, PREDIMED Study Investigators. Reduction in the incidence of type 2 diabetes with the Mediterranean diet: results of the PREDIMED-Reus nutrition intervention randomized trial. Diabetes Care. 2011;34(1):14-9.

17. Lindström J, Neumann A, Sheppard KE, Gilis-Januszewska A, Greaves CI, Handke U, Pajunen P, Puhl S, Pölönen A, Rissanen A, Roden M, Stemper T, Telle-Hjellset V, Tuomilehto J, Velickiene D, Schwarz PE, Acosta T, Adler M, AlKerwi A, Barengo N, Barengo R, Boavida JM, Charlesworth K, Christov V, Claussen B, Cos X, Cosson E, Deceukelier S, Dimitrijevic-Sreckovic V, Djordjevic P, Evans P, Felton AM, Fischer M, Gabriel-Sanchez R, GilisJanuszewska A, Goldfracht M, Gomez JL, Greaves CJ, Hall M, Handke U, Hauner H, Herbst J, Hermanns N, Herrebrugh L, Huber C, Hühmer U, Huttunen J, Jotic A, Kamenov Z, Karadeniz S, Katsilambros N, Khalangot M, Kissimova-Skarbek K, Köhler D, Kopp V, Kronsbein P, Kulzer B, Kyne-
Grzebalski D, Lalic K, Lalic N, Landgraf R, Lee-Barkey YH, Liatis S, Lindström J, Makrilakis K, McIntosh C, McKee M, Mesquita AC, Misina D, Muylle F, Neumann A, Paiva AC, Pajunen P, Paulweber B, Peltonen M, Perrenoud L, Pfeiffer A, Pölönen A, Puhl S, Raposo F, Reinehr T, Rissanen A, Robinson C, Roden M, Rothe U, Saaristo T, Scholl J, Schwarz PE, Sheppard KE, Spiers S, Stemper T, Stratmann B, Szendroedi J, Szybinski Z, Tankova T, Telle-Hjellset V, Terry G, Tolks D, Toti F, Tuomilehto J, Undeutsch A, Valadas C, Valensi P, Velickiene D, Vermunt $P$, Weiss $R$, Wens J, Yilmaz T. Take action to prevent diabetes--the IMAGE toolkit for the prevention of type 2 diabetes in Europe. Horm Metab Res. 2010;42(Suppl 1):S37-55.

18. European Public Health Association EUPHA: Healthy and Sustainable Diets for European Countries. 2017, https://eupha.org/repository/advocacy/ EUPHA_report_on_healthy_and_sustainable_diets_20-05-2017.pdf. Accessed 15 Oct 2019.

19. Huseinovic E, Winkvist A, Slimani N, Park MK, Freisling $H$, Boeing $H$, Buckland G, Schwingshackl L, Weiderpass E, Rostgaard-Hansen AL, Tjønneland A, Affret A, Boutron-Ruault MC, Fagherazzi G, Katzke V, Kühn T, Naska A, Orfanos P, Trichopoulou A, Pala V, Palli D, Ricceri F, Santucci de Magistris M, Tumino R, Engeset D, Enget T, Skeie G, Barricarte A, Bonet CB, Chirlaque MD, Amiano P, Quirós JR, Sánchez MJ, Dias JA, Drake I, Wennberg M, Boer J, Ocké MC, Verschuren W, Lassale C, Perez-Cornago A, Riboli E, Ward H, Forslund HB. Meal patterns across ten European countries - results from the European Prospective Investigation into Cancer and Nutrition (EPIC) calibration study. Public Health Nutr. 2016;19(15):2769-80.

20. Lassale C, Gunter MJ, Romaguera D, Peelen LM, Van der Schouw YT, Beulens JW, Freisling H, Muller DC, Ferrari P, Huybrechts I, Fagherazzi G, Boutron-Ruault MC, Affret A, Overvad K, Dahm CC, Olsen A, Roswall N, Tsilidis KK, Katzke VA, Kühn T, Buijsse B, Quirós JR, Sánchez-Cantalejo E, Etxezarreta N, Huerta JM, Barricarte A, Bonet C, Khaw KT, Key TJ, Trichopoulou A, Bamia C, Lagiou P, Palli D, Agnoli C, Tumino R, Fasanelli F, Panico S, Bueno-de-Mesquita HB, Boer JM, Sonestedt E, Nilsson LM, Renström F, Weiderpass E, Skeie G, Lund E, Moons KG, Riboli E, Tzoulaki I. Diet Quality Scores and Prediction of All-Cause, Cardiovascular and Cancer Mortality in a Pan-European Cohort Study. PLoS One. 2016;11(7):e0159025.

\section{Publisher's Note}

Springer Nature remains neutral with regard to jurisdictional claims in published maps and institutional affiliations.

\section{Ready to submit your research? Choose BMC and benefit from:}

- fast, convenient online submission

- thorough peer review by experienced researchers in your field

- rapid publication on acceptance

- support for research data, including large and complex data types

- gold Open Access which fosters wider collaboration and increased citations

- maximum visibility for your research: over $100 \mathrm{M}$ website views per year

At $\mathrm{BMC}$, research is always in progress.

Learn more biomedcentral.com/submission 